\title{
The performative effects of diagnosis
}

\section{Thinking gender and sexuality through diagnostic politics}

\author{
by Sebastian Mohr
}

\begin{abstract}
In this article, I suggest the performative effects of diagnosis as an analytical tool to explore the transformations in people's intimate lives that being diagnosed brings with it. As an analytical term, I understand the performative effects of diagnosis to describe trajectories in people's intimate lives that emerge in the interplay between a person's intimate sense of self, that is, their gendered and sexualed self-perceptions, and the logics and norms contained in medical diagnoses. I develop this term in the context of ethnographic research on Danish war veterans' understandings of and experiences with intimacy and extrapolate it conceptually in this article through scholarship in feminist theory, trans studies, STS, and medical anthropology and sociology. The argument that I make throughout is that the performative effects of diagnosis allows scholars to explore transformations in people's intimate lives without a foreclosure about the normative dimensions of these transformations. In that sense, rather than only asking how biopolitical and cis- and heteronormative normalcy constitutes itself, the performative effects of diagnosis provide the opportunity to explore how these dimensions are (re)configured and (un)done in and through medicalized intimacies.
\end{abstract}

KEYWORDS: biosociality, identity, intimacy, medicalization, performativity, sexuality

SEBASTIAN MOHR is senior lecturer of gender studies at Karlstad University, Sweden. Sebastian is interested in how we become subjects with a sense of self, identity, and belonging and what role gender, sexuality, and intimacy play thereby. He attends to this interplay ethnographically in the areas of (digital) health technology, reproductive biomedicine, military masculinities, and gender equality. Sebastian is the author of Being a Sperm Donor: Masculinity, Sexuality, and Biosociality in Denmark (Berghahn, 2018). 
I felt less satisfied with my sex life in my disease unconscious period (min ikke sygdomsbevidste periode), you know, when I was sick but was not aware of it. For about 20 years, sex was really, really boring, something mechanical that didn't really give me any kind of satisfaction. It was only to have release (udløsning), you know, the plain physical urge (tvang) that was there. (...) But I wasn't aware that it should have been any different. It wasn't as if I was unsatisfied with it. I just had a more general feeling that something was missing in my life, and my psychologist back then also said that I might have a depression. I had the feeling that something was missing and I thought that this had to do with work, you know. But it was actually my feelings that I wasn't in contact with, that was what I missed, what I was lacking. There was a hole inside of me, you know. And because I wasn't aware of that at the time, I was also not aware that there was something wrong with the things I did, sex for example.

Jim, Danish war veteran in his 40 s

This article is concerned with what I call the performative effects of diagnosis. The performative effects of diagnosis might be understood as trajectories in people's intimate lives that open up through the interplay between medical diagnoses on the one hand and people's gendered and sexualed self-perceptions on the other. As such, the performative effects of diagnosis as an analytical term are concerned with how people construct a meaningful intimate biography in light of being diagnosed, that is, they not only describe reality in light of a diagnosis but rather explore the creation of a new intimate reality in people's lives due to being diagnosed. Jim, a Danish war veteran in his 40 s and whom the above quote is from, might be said to put in a nutshell what the performative effects of diagnosis are about. They describe changes in how people conceive of their intimate lives and how they make these changes meaningful in terms of living intimacy when having a medical diagnosis. In Jim's case, these kinds of changes became apparent in how he narrated his own intimate life over the course of different conversations with me. He divided his life into a disease unconscious period and a disease conscious period. This division of his life, into a period in which he was suffering from post-traumatic stress disorder (PTSD) without being aware of it and a period in which he was aware of this particular diagnosis and thus also able to do something about it, characterized not only how he thought about himself but also how his intimate life played out. What is more, once being able to think of himself in terms of being diagnosed with PTSD, Jim reconstructed his intimate biography in light of this new self-perception, or as he puts it himself above: "There was a hole inside of me, you know. And because I wasn't aware of that at the time, I was also not aware that there was something wrong with the things I did, sex for example."

Narrating his life through this division, Jim points to the importance of diagnoses not only in terms of pathology, medical treatment, and healing, but also in terms of his self-perception as a man, an intimate partner, and not least a human being longing for meaningful sexual relations. Taking Jim's narrative seriously in this sense, in this article I thus want to offer the performative effects of diagnosis as an analytical tool, which allows scholars to ask what medical diagnoses actually do in people's intimate lives. While health research and health studies often only focus on solving the (medical) problems at hand, and while gender studies often focus on the subjugating force of medicalization and its intertwinement with cisand heteronormative assumptions and not least patriarchal gender relations, the tool that I am offering here rather strives to explore the transformative potential of living medicalized intimacies. As such, with this article I wish to intervene in both scholarly discussions of (veteran) health as well as in discussions of medicalization in gender studies by offering the performative effects of diagnosis as a tool that allows for exploring what it actually means to live intimate-sexual lives in light of medical diagnoses.

I will proceed by first giving you a more detailed account of Jim's life through a portrait that 
emerged from the conversations I had with him. While this article is not an in-depth analysis of his narrative but rather a conceptual contribution to discussions within gender studies and (veteran) health studies about how gender and sexuality interplay with medical diagnoses and the politics and logics contained within them, I nevertheless want to put Jim's portrait at the beginning of my conceptual reflections. I think that it is important to recognize the significance that empirical accounts have for the development of theoretical concepts. In a second step, I will provide you with an account of the theoretical underpinnings of the performative effects of diagnosis. To do so, I weave together feminist notions of performativity, discussions of (bio)medicalization and biosociality in medical anthropology and sociology and science and technology studies (STS), and last but not least trans studies scholarship on the (bio)medical regulation of trans folks' gender identity. This will further situate the concept by making it knowable through existing thought universes. I will end the article with a summary of the most important points and their implications for scholarship interested in the interplay between gender, sexuality, and medical diagnoses.

\section{Situating the performative effects of diagnosis ethnographically - Jim's portrait}

Jim is a Danish war veteran in his forties. He has been married a couple of times and has children from these marriages. On his first deployment when he was only 20 years old, he is now on early retirement due to occupational injuries and impairments resulting from that first deployment. Jim has been on three deployments altogether between the 1990s and 2010. In 2011, Jim was diagnosed with PTSD, personality change, obsessive-compulsive disorder, depression, as well as anxiety, and was at the time of our conversations taking Valdoxan, used to treat depression, and Imozop, a prescription medicine targeting sleeping problems. But Jim has also had periods of self-medication with alcohol. In addition, Jim has gone through a variety of different therapeutic treatments ranging from help by an occupational psychologist organized by his last employer, specialized clinical treatment for military personnel in the public health care system, to peer group sexual therapy with other veterans organized by an autodidact sexual therapist. Following this last therapy, Jim began with a training course to become a sexual therapist himself.

Jim was one of 12 veterans that I interviewed. Research took place between 2016 and 2018 and had the objective of exploring Danish war veterans' understandings of and experiences with intimacy. Besides interviewing veterans about their lives, I also worked as a volunteer at a home for veterans at least once a week and conducted participant observation at relationship courses offered by the Danish Veteran Center for current and former military personnel and their partners. As with all of my interviewees, I had three conversations with Jim: one about his life and career as a soldier, one about his relations to loved ones, family, friends, colleagues, and other acquaintances, and one about his sex life.

Jim's narrative was determined by one fundamental division: a period in his life in which he was suffering from PTSD without being aware of it - his disease unconscious period - and his current life now that he is aware of the fact that he has PTSD and thus can do something about it his disease conscious period. This division was the main reference point when talking about his intimate and sexual life. What was most important for Jim when explaining his intimate and sexual life to me was that being diagnosed with PTSD enabled him to get into contact with his feelings again. What is more, PTSD as a diagnosis also enabled him to look at his intimate relations in a different way, remaking them now that he regards himself as someone with PTSD.

This became most obvious when Jim compared his former marriages with romantic relationships he had after being diagnosed. While he talked about his intimate relations to his former wives as something that just needed to be done, he understood his intimate relations with his girlfriends 
as emotional, sensual, and personally involved. Talking about his current sex life, Jim said:

I have more and better sex now than before. You know, those emotions, they add a totally different level, it is like there is a different layer on top now. I can feel the people I am with, and they can feel me. It has become much more, it is really much more sensual and intimate than it was before.

In contrast, he talked about his relationship to one of his wives in the following way:

When I came back from deployment, our relationship had changed because, without knowing it, I had gotten PTSD. And the emotional emptiness (følelsesforladthed) which comes with that, that began at that point, so that I didn't have the same feelings for her anymore. I distanced myself from her and I also had difficulties sleeping, headaches, and was short-tempered (opfarende), all those things that come with PTSD.

In addition to talking about his intimate life in light of his PTSD diagnosis, Jim also attributed what he described as his evolving sexual openness to his current awareness about the shortcomings of PTSD. While never considering himself capable of or interested in sexual practices other than monogamous heterosexual penetrative intercourse before his PTSD diagnosis, after being diagnosed and subsequent therapeutic experiences, Jim started to experiment with sexual relations that involved other body parts than his penis and forms of sexual stimulation other than heterosexual penetrative intercourse. To that end, Jim talked for example about trying polyamorous intimate relations, experimenting with sexual dominance and submission, watching other men engage sexually with each other, and having his prostate stimulated anally by other people. Talking about this change in his sexual life, he said:

I think my sex life really changes when I start to connect with my feelings again, when I get to know myself. And those are more or less only the last three years of my life. Before that, there wasn't really any development. One third of my life is all the way until I am reported sick, one third is when I am ill, and then the last part now that I am in contact with my feelings again.

The difference that the diagnostic event made in Jim's way of living intimacy needs to be accounted for conceptually. This is what the performative effects of diagnosis aspire to do: to provide an analytical tool that allows for the exploration of the intimate potentials that emerge in the interplay between people's sense of self in terms of gender and sexuality on the one hand, and the regulatory moments contained in medical diagnoses on the other. Jim's intimate biography first gave meaning to him after he was diagnosed with PTSD. The diagnosis enabled him to find words for and meaning in the sexual and intimate relations he has had during his lifetime, or, in other words, the performative effects of diagnosis opened a space for him to understand, live, and experience intimacy differently. And rather than only describing a status quo, Jim talks about how new intimate realities in terms of gender and sexuality came into being.

Jim's way of narrating his intimate life made me aware of the importance of a conceptual intervention in discussions of medical diagnosis and medicalization. While (veteran) health studies most likely evaluate Jim's and other veterans' lives in terms of medical betterment and therapeutic innovation, and while gender studies more often than not rightly point to cis- and heteronormative dimensions and the subjugating power of medicalization, the performative effects of diagnosis aim at opening up an analytical space rather than foreclosing it. They allow for an exploration of new intimate realities that diagnoses bring about. Thus, the analytical starting point of the performative effects of diagnosis is that transformations are taking place in people's gendered and sexualed self-perceptions and not that these transformations are good or bad or large or small. How I support this argument theoretically will be the focal point in the following conceptual discussion. 


\section{Situating the performative effects of diagnosis conceptually, part one- feminist legacies}

The advent of diagnosis remakes Jim's intimate life as he knows it, with far reaching consequences for his gender and sexual subjectivity. From a normative position that conceives of emotional introspection, therapeutic intervention, and medical treatment as a way of betterment, the changes in Jim's intimate life might be said to be positive. That is at least also how Jim himself understands his intimate biography. Yet while the performative effects of diagnosis might certainly provoke this kind of meaning making, the concept is not only concerned with positivity, betterment, or improvement. Rather, the performative effects of diagnosis describe changes in or the (re)making of intimacy as a transformative process without a normative claim about whether or not those transformations are good.

Thinking of the (re)making of intimacy in this way, I am inspired by feminist concepts of gender performativity, by scholarship in medical anthropology and sociology and STS interested in questions of biomedicalization, biosociality, and subjectivation, and not least by work of scholars in trans studies looking at the interplay between gender identity and (bio)medical regulation. I will first attend to feminist theorizations of performativity. Then, I will connect these ideas with ways of thinking subjectivation in times of biosociality. In a third step, I will turn to scholarship in trans studies in order to think through questions of gender identity in light of (bio)medical regulation and practice.

While public discussions often reduce gender and sexuality to relatively stable and fixed characteristics of human beings, the histories of gender and sexuality (as ways of describing and understanding people and their intimate relations to one another) actually show that gender and sexuality are anything but stable and fixed. What is more, using them as categories for defining and explaining people's behavior has ramifications for how people understand themselves and, not least, for how gender and sexual norms take hold in people's lives, that is, they are performative in the sense that they not only describe reality but actually help reality come into being. When heterosexuality and homosexuality as categorical terms were coined in the middle of the $19^{\text {th }}$ century for example, both terms connoted equally "perverse" behavior since both did not have a procreative objective (Katz 1996). Yet at the beginning of the $20^{\text {th }}$ century, the categorical understanding of heterosexuality had come to describe normalcy, leaving behind homosexuality as pathology, disease, deviance, and not least punishable offense (Foucault 1990). This had real consequences in people's lives. Whereas people understood and identified as heterosexual were mostly freed from medical, therapeutic, and legal interventions, people categorized as homosexual on the other hand were subjected to pathologization, medicalization, and criminalization (Terry 1999).

A similar dynamic was at work when gender as a concept made its debut, first in the clinical treatment of intersex and trans people and later in the social sciences and especially feminism. John Money, a psychologist with a specialization in intersexuality, developed a clinical treatment regime for intersex and trans individuals in the 1950s. This treatment regime had the objective of turning people into clearly identifiable men and women in cisand heteronormative terms. For that purpose, John Money offered gender as a way to think about his patients' non-dichotomous femininities and masculinities (Germon 2009; Goldie 2014). Conceiving of gender as a way of helping people adjust to what was at the time identified as the best (in the sense of normatively least disturbing) ways of being a man or woman, gender had real life consequences. Gender in Money's terms helped bring a particular reality - cis- and heteronormativity - into being by (violently) transforming people's intimate sense of self. Not only did gender in Money's terms force people to take on identities as unambiguous women and men. Money's treatment regime also changed their bodily, affective, and emotional capacities by operating cis-gender into their bodies. In other words, gender emerges already here as performative since it not only describes a reality but rather brings new intimate realities into being. 
But gender as such a transformative force also played a central role in social science and especially feminist thinking following Money's initial conceptualization. Whereas gender was productive by giving feminists a way of conceptualizing power relations between women and men (Ortner 1972; Rubin 1975; Millett 1970) and thus helped to legitimize and subsequently institutionalize feminism and gender studies, it was also performative in terms of creating new identifications and forms of subjectivation. Once gender was available as a way of thinking about the social dynamics of sex categorizations, women and men could critically reflect on their personal and intimate life through a vocabulary of (in)equality. This probably became most visible in radical feminist ideas, which posed that intimacy and sexuality are central arenas in which gender as a power relation plays out and is (un)done (Rubin 1984; Dworkin 1981). In other words, gender's performative dimensions (re)created (new) intimate realities for people through for example feminist masturbation courses (Dodson 2004) and feminist sex toy stores (Comella 2017) but also anti-pornography campaigns (MacKinnon and Dworkin 1997) and men's rights groups (Kimmel 1987).

Yet it was first with the work of Judith Butler at the end of the 1980s and the beginning of the 1990s that Western feminism actually adapted a vocabulary that enabled scholars to talk about gender as performative (1986, 1990, 1993). Itself the result of the productive force of feminist theorizing, Butler's work offered a critique of how Western feminists conceptualized gender at the time. While feminists had offered gender as a way of thinking about the social inequalities between women and men, Butler made the radical step of questioning the very distinction between sex and gender. Rather than simply arguing that gender was done as part of social relations as other contemporaries did (West and Zimmerman 1987; Carrigan, Connell, and Lee 1985; Crenshaw 1991), Butler inquired about the effects that the distinction between sex on the one hand and gender on the other might have for Western feminist epistemology, critique, and activism.

Her basic argument in Gender Trouble was as simple as it was revolutionary: gender is the normative basis upon which sex is build (Butler 1990). To put it differently, in order for sex to work as a binary classificatory code there needs to be a normative understanding of what makes unambiguous women and men, that is, rather than gender being the social expression of sex, gender is the social framework within which binary sex emerges. With this argument, Butler pushed feminist theorizing to engage with the performative dimensions of gender rather than only with its social manifestations since the object of inquiry in Butler's argument encompassed gender as a normative as well as transformative feature of social life. Thus in Butler's argument, gender is performative because it (re)creates reality in its conceptual, discursive, and material dimensions.

With this argument, Butler was able to point to the effects that the distinction between sex and gender had for feminist theorizing and activism. Holding on to a sex-gender divide, Butler argued, binary feminism is not able to account for the diversity of female subjectivation since woman (as a clearly sexed individual) remained its only legitimate subject. In addition, Butler insisted, binary feminism rests on a heterosexual matrix and thus perpetuates heterosexuality as a norm of subjectivation while also limiting the investigation of gender to only its subjugating elements, thereby missing its subversive potential. In Butler's account gender emerges as performative in at least three ways: 1) gender brings about particular forms of feminist theorizing and activism; 2) gender (re)creates its own normative ontology by perpetuating cis- and heteronormativity; and 3) gender simultaneously subverts this ontology by creating avenues for potential other futures.

This understanding is important for the conceptualization of the performative effects of diagnosis. The performative effects of diagnosis are concerned with the dynamic between normative de- and proscriptions of reality as well as with the subversive potential contained in the event of diagnosis. Thus, diagnoses might be said to be performative in at least three ways. First, diagnoses (re)instate a particular line of reasoning in the lives of people who are diagnosed, namely the reasoning employed in (bio)medical and therapeutic 
discourses. Secondly, diagnoses (re)create a specific normative ontology through the perpetuation of the intimate self in terms of the biopolitically responsible and cis- and heteronormatively gendered subject. And thirdly, diagnoses are also performative because they subvert their own ontological framework by opening up potential futures beyond biopolitical and cis- and heteronormative normalcy. That is to say, medical diagnoses have performative effects in the sense that they not simply describe a certain condition identified by medicine as pathological and in need of treatment but rather that medical diagnoses bring about new intimate realities in people's lives. Diagnostic events and the effects they have transform how people perceive themselves in terms of gender and sexuality and thus also how they live their intimate lives as gendered and sexualed individuals.

\section{Situating the performative effects of diagnosis conceptually, part two - (bio)medicalization and biosociality}

One could argue that the performative effects of diagnosis are old news. For scholars interested in what difference medicine and medical treatment make in the daily lives of people, the question of how medicine changes people's lives is certainly not a new one. Yet while this question has been posed time and again, exploring it as a matter of intimate relations and as a matter of emerging intimate subjectivities, as I have laid out, has not necessarily been the analytical focus. However, that is precisely what the performative effects of diagnosis are concerned with. They are about the meaningful differences that diagnoses (and subsequent treatment) make in the intimate lives of people. As such, the performative effects of diagnosis explore how (bio)medical and therapeutic reasoning take hold in people's lives, what kinds of intimate selves that process perpetuates, and what subversive dynamics this process of intimate becoming contains or opens up for.

In 1951, Talcott Parsons offered an analysis of medicine as part of a larger system of social control (2005). Thereby he coined the term sick role to describe a patient's social positioning through which their deviance from their usual social role becomes legitimate and therewith a way of upholding the social order. Thus in Parsons' terms, being a patient is not plainly about becoming healthy again. As he understood it, being a patient also means to enter a social contract that legitimizes people's temporary deviation from their usual societal obligations while also binding them to existing social norms. Or, put differently, by accepting the obligations of the sick role, patients are allowed to abstain from what is otherwise expected of them, like for example going to work or fulfilling roles as parents, friends, and sexual partners.

This might be said to be a conceptual starting point for how to think subjectivation or intimate subjectivities in relation to the performative effects of diagnosis. The sick role contains an element of (temporarily) changed identity and reality since through the sick role, patients might be said to begin thinking of themselves and their intimate capacities in a new way. Thus, while Parsons and those who followed him never conceptualized it as such, one may say that the sick role is performative in a double sense. It upholds the existing social order by creating a temporarily legitimate deviation from the norm while simultaneously bringing about new intimate realities that have the potential to subvert this norm, since patients are allowed to live other intimate lives as long as they accept the obligations of the sick role.

Irving Zola (1972) and his student Peter Conrad (2007) took up this idea of medicine as an institution of social control and developed what today is known as medicalization. Medicalization might be understood as the process through which social life becomes comprehensible as a medical matter. For something to be medicalized, it needs to be contained within a medical logic, be described with medical language, and be taken care of through medical treatment. While this conceptual development might seem unspectacular for some since, in their eyes, that is what medicine does, namely helping people to get back to normal by enrolling them into a treatment regime, 
it was rather path-breaking for discussions within medical sociology at the time. Medicalization does more than simply pointing out the obvious. Medicalization highlights how medicine's sphere of influence extends, that is, how the social control that medicine and medical treatment exert proliferates beyond medicine's original mandate.

Extending the idea of the sick role, Zola and Conrad thus conceptually developed the performative dimensions of medical authority in the daily lives of people. In that sense, medicalization could be understood as performative because it leads to the proliferation of medical and therapeutic reasoning and thus to the production of new intimate realities. For example, the increasing use of medical substances among gay men against HIV-infections (called PrEP or pre-exposure prophylaxis) can be understood as a form of medicalized intimacy (Dean 2015; Martinez-Lacabe 2019; Young, Flowers, and McDaid 2016). Through the analytical lens of medicalization, gay men using PrEP might be said to not only decrease their likelihood of being infected with HIV. PrEP also extends (bio)medical and not least bio-political control over areas of intimate life that queer activists had fought hard for to be liberated from medical pathologization. At the same time though, one might argue, it is exactly this process of medicalization that creates the possibility of queer intimacy by protecting queer bodies from death. However one would normatively position the effects of medicalization, this process might be said to be performative because it both extends existing norms of bio-political responsibility while also challenging them by creating pathways for other potential queer futures. In other words, medicine not only heals people, it also transforms their social and intimate life.

Feminists took up medicalization as part of their theorizing, especially in relation to reproductive technologies and reproductive biomedicine (Franklin 1997; Clarke 1998; Rapp 1999; Martin 2001). Some feminists looked at (bio)medical interventions in people's intimate lives and bodies critically because they were rightly weary of the patriarchal dynamics involved in medical control. Other feminists praised the potential of new medical technologies to free the female subject from traditional gender relations (Thompson 2005; Franklin and McNeil 1988; Koch 1990). Although discussions among feminists about the social consequences of reproductive technologies are still ongoing, a shift nonetheless occurred from viewing medicine purely as an institution of social control towards exploring (bio)medicine as a field of potentiality (Taussig, Hoeyer, and Helmreich 2013). Important for this shift were, amongst other things, two conceptual terms: biomedicalization and biosociality.

While biomedicalization was thought of as a conceptual overhaul of the original medicalization thesis (Clarke et al. 2003), biosociality developed as part of engagements within anthropology with the Human Genome Initiative inspired by Michel Foucault's conceptual vocabulary (Rabinow 1996). In the re-development of the medicalization thesis, Adele Clarke and colleagues offered the term biomedicalization as a way of analytically grasping the transformations in sociality and identities through biomedicine $(2003 ; 2010)$. While much of the scholarship up to that point had been concerned with how (bio)medicine keeps certain power and gender relations in place, Clarke and scholars adopting her conceptual ideas were rather interested in what kinds of new identities and forms of identification (bio)medical technologies enable. What came in focus were the performative dimensions of the proliferation of (bio)medicine in people's daily lives. Along a similar line of argument, Paul Rabinow offered the term biosociality in order to account for the changes in how people understand themselves as well as their social relations through the development of and interventions in social life through biotechnologies (1996). Biomedicalization and biosociality thus enabled scholars to ask questions about the performative effects that biomedicine and biotechnology bring about in people's ways of identifying, relating, and not least being intimate.

While the medicalization of the female body had been in focus for quite a while at that time, the medicalization of and its effects for men, male bodies, and masculinities was less so (Rosenfeld and Faircloth 2006; Oudshoorn 2003). That changed 
in line with increasing attention on men's health (Robertson 2007). Masculinity studies scholars became involved with biomedical questions and health scholars adopted concepts from within feminism and masculinity studies in their work. This paved the way for investigations into and conceptualizations of the differences diagnoses, illness, and treatment make in men's intimate lives. Concepts such as Marcia Inhorn's emergent masculinities (Inhorn 2012) or Emily Wentzell's composite masculinities (Wentzell 2013) are just two examples of a number of concepts offered in order to analytically explore and comprehend the interplay between gender identity, medical technology, treatment, and diagnosis. As I have suggested, one might also comprehend this interplay in terms of biosocial subjectivation, that is, the continuous "invocation of the subject in terms of biomedical registers and biopolitical valuations" (Mohr 2018, 7). While different concepts address different dimensions of people's experiences and meaning making, they all have in common an interest in what kinds of new realities (bio)medical interventions create and in particular how gender is implicated in that process. Diagnoses not only put a new name on something that a patient did not know how to address before, as Annemarie Goldstein Jutel puts it (2011). Rather, diagnoses performatively transform how people think of themselves in an intimate sense and what kind of intimate lives they are (not) able to live. I will elaborate on this point now by discussing scholarship in trans studies on the interplay between gender identity and medical regulation.

\section{Situating the performative effects of diagnosis conceptually, part three - trans identity and medical regulation}

The performative effects of diagnosis are probably most urgently felt by those whose gender and sexual identities and bodily dispositions are framed as pathological by the mainstream model of cis- and heteronormative and ableist medicine as we know it today in most western-democratic societies. It is their bodies and identities that are diagnosed as being outside of what medicine (and in extension society) considers "normal". The criminalization and pathologization of gay men and lesbian women serve as strong reminders of what kinds of effects diagnoses can have in peoples' intimate lives. Medical understandings of homosexuality as a pathology not only provided grounds for widespread and continuous discrimination of lesbian women and gay men, it also had performative effects in the sense that lesbian and gay intimacies were (and one might even argue for some continue to be) a source of shame.

The medicalization and pathologization of trans folks' gender identity points to similar dynamics. It is through its influence as a social institution that medicine exerts is definitional power in terms of diagnosis, with very clear consequences for what kinds of lives trans people are (not) allowed to live (Inch 2016). Yet while the performative effects of gender dysphoria limit trans people's intimate possibilities in important ways, trans people also engage with the possibilities that the medicalization of gender identity and sexuality bring with them such as access to transition technologies and social recognition and acceptance (Johnson 2019; Burke 2011). Thus, the performative effects of diagnosis do not solely describe a subjugating power but rather a dynamic entanglement between people's intimate sense of self, normative assumptions around gender and sexuality, and at the same time continuous re-negotiations of these very norms.

Despite arguments to the contrary in certain parts of western LGBTQI activism, trans and intersex as categorical (self)definitions are neither culturally nor historically ubiquitous and self-evident. Rather, trans and intersex as both medical classifications as well as modes of identifying are particular in the sense that they emerged in a specific medico-legal and activist space bound to Western European and American societies (Stryker 2008). What is more, trans and intersex as classificatory regimes and terms of identification are bound to the interplay between diagnostic practice on the one hand and appropriations of and resistances to this practice on the other (Horncastle 2018; Paine 2018; Plemons 2014). 
The work of historian and trans studies scholar Sølve Holm is directly concerned with this dynamic. In their work, they look at the medical and legal regulation of intersex and trans people in Denmark between 1902 and 1973 (2017). Holm addresses the question: what kinds of historical backgrounds enabled medical professionals in Denmark to make the claim that intersex and trans lives in self-identified terms would neither be possible nor desirable and should therefore be made to fit into the binary framework of cis- and heteronormativity? Attending to this question through the analysis of a variety of different historical sources, Holm gives an intriguing account of how intersex and trans lives and intimacies were dis- and enabled in Denmark. Looking specifically at the lives of two protagonists, Holm makes understandable just how performative the interplay is between medical and legal regulation on the one hand and intersex and trans people's identifications on the other. Not only are subjects made, both as patients in need of protection and as self-authoritative individuals successfully playing the system, but also welfare states organized around the legal and clinical management of gender identity.

At the center of it all are the lived intimate realities of intersex and trans people, who make claims to live more livable lives, as Holm puts it. Yet rather than medicine exerting its force as an institution of social control only, by making people into cis- and heteronormative individuals, intersex and trans people's intimate sense of self becomes an authoritative dimension that remakes diagnostic practice. At the same time, this practice enables intersex and trans people to live the lives they want to live. As Holm puts it themselves in the concluding chapter of their thesis: while both protagonists

articulate clearly that they wish to be recognised as a man and a woman respectively, in recounting the events of their lives, neither of them tells a story about having always experienced themselves as being this in essence. Rather, their accounts are of movements between different gendersexed positions, which are to a great extent dependent on the notions, values, and material conditions of the social situations in which they find themselves. And they are about growing urges to move to materialdiscursive places and spaces (...) that feel more comfortable to them, and where they may recognize themselves in the ways in which others relate to them. (Holm 2017, 380)

What emerges here is thus a notion of a performative potential that arises from the interplay between medicine as a social institution shaping bodies and identities on the one hand and bodies and identities talking back to this institution on the other. Without necessarily being able to say whether those intimate lives were the best ones possible (in a normative sense), it is this performative potential that opens the possibility for particular intimate lives to emerge and take shape. Or put differently, the particular intimate lives of Holm's protagonists would not have been possible without "the notions, values, and material conditions" (Ibid.) that the performative effects of diagnosis brought about.

Anthropologist and trans studies scholar Eric Plemons engages with the effects of diagnosis and treatment in his work on facial feminization surgery (2017). Following the work of two surgeons in the USA and the trajectories of American trans women undergoing this surgical procedure, in his ethnography The Look of a Woman Plemons opens the black box of trans medical practice. Facial feminization in Plemons' account is not plainly a surgical procedure. Rather, he unpacks it ethnographically and thereby makes it understandable as actively shaping and being shaped by gender. For once, the surgical procedure itself is the result of the performative potential of gender since surgeons' ways of conceptualizing and conducting the procedure are the results of particular gendered world makings. Yet through the surgical procedure, gender also takes form in trans women's bodies, and what is more, the procedure likewise has a profound influence on how these women view themselves (for better or worse) and thus how they envision and actually live their intimate lives. 
This performative dimension becomes particularly clear in Rachel's story, one of the protagonists in Plemon's book. In her mid-fifties and just recovering from surgery when Plemons meets her for the first time, Rachel was very enthusiastic and accordingly also "bursting with the optimism of a yet unknown future." (Ibid., 136) Enticed by the possibility of living a different intimate life due to the performative potential of facial feminization, Rachel's intimate sense of self changed since surgery made her into the woman she desired to be. And although at the time Plemons met her, Rachel had not seen her new face yet, she nonetheless talked about herself as holistically transformed:

Under its bandages her new face - still tender, bruised, and cut - held the possibility of a radically new identity in which she could be a stranger to everyone she knew. That sounded scary to me, but to Rachel the prospect was 'wonderful.' (Ibid., 138)

Far from only changing her body in a radical way, facial feminization surgery creates a space in which Rachel is able to construct a new identity, enabling her to live a different kind of intimate life. While Rachel's life and that of many other trans women is characterized by medicalization and its diagnostic logics, something that might be understood as a form of social control, Rachel's autonomy and her ability to create the livable life she wants to lead are also enabled by medical practice and its normative politics. Medical diagnosis, practice, and treatment are not purely ways of controlling bodies and identities. They are also about potential intimacies, which individuals can(not) and (do not) want to live.

It is in this complex dynamic of social control, potentiality, normativity, and subversion that I want to position the performative effects of diagnosis. Understood as intimate trajectories emerging through the interplay between people's sense of self as a gendered and sexualed subject on the one hand and the norms and logics of diagnoses on the other, the performative effects of diagnosis are not an ontological claim about whether living intimate lives in light of a medical diagnosis is a good or a bad thing, improves or worsens people's well-being, multiplies or limits their agency. Rather, I am offering the performative effects of diagnosis as an analytical tool that allows us to investigate what difference the event of diagnosis makes in people's intimate lives. As such, the performative effects of diagnosis pay tribute to the complexity that living intimate lives with a diagnosis entails and the multiple and sometimes contradictory dynamics that medical potentiality unfolds in people's intimacies. Going back to Jim's narrative at the very beginning of this article, being diagnosed with PTSD has both enabling and disabling effects, just as the diagnostic logic of medicine has both enabling and disabling effects in the lives of women like Rachel. While Jim is at times heavily medicated, experiences erectile difficulty, and as a result has to face his own shortcomings as a sexual partner, being diagnosed with PTSD also enabled him to enter into different and, most importantly for himself, more meaningful intimate relations than was the case before the advent of diagnosis. And analytically grasping that kind of complexity opens the possibility to be curious about what actually happens in people's intimate lives rather than describing their lives only in terms of either the positive or negative consequences of medical authority and (gender) normativity.

\section{Concluding remarks}

I want to end by pointing out what I consider the most important dimensions of the performative effects of diagnosis in a conceptual-analytical sense. First, the performative effects of diagnosis are embedded in the lived realities of actual people, and they therefore need to be contextualized in those intimacies when attending to them. Second, the performative effects of diagnosis are concerned with transformative - that is remaking reality - dynamics in people's intimate lives in light of medical diagnoses, independent of how one perceives those dynamics in a normative sense (i.e. good or bad; large or small), and they therefore also need to be explored as such. And third, the performative effects of diagnosis are performative on 
at least three levels: they (re)instate (bio)medical and therapeutic reasoning in people's lives; they (re)create people's intimate selves in terms of biopolitical responsibility and cis- and heteronormativity; and they simultaneously subvert these normative dimensions by installing potential futures that go beyond the normalcy of biopolitics and cisand heternormativity. As such, the performative effects of diagnosis explore how (bio)medical and therapeutic reasoning take hold in people's lives, what kinds of intimate selves that process perpetuates, and what subversive dynamics this process of intimate becoming contains or opens up for. Diagnoses have real effects in people's lives. They are not only a matter of describing a health status. Rather, they change people's intimate possibilities, and precisely therefore it is important to develop a conceptual language for these changes, so that scholars can attend analytically to how changes in people's lives play out rather than only understanding these changes as reifications of the status quo, be that biopolitics, medical authority, or cis- and heteronormativity.

I am not proposing the performative effects of diagnosis as just another set of analytical ideas that solely helps to make the important point that we live in patriarchal and cis- and heteronormative societies. Equally, I am not proposing this analytical tool only to point to the necessity of solving medical and health problems. Rather, I am proposing the performative effects of diagnosis as an important avenue to pursue for scholars of all disciplines if they want to explore and understand what changes and transformations take place in people's intimate lives through the advent of diagnosis.
For people in (veteran) health studies this would mean not to regard changes in people's intimate sense of self as side effects that can be ignored. Rather, the performative effects of diagnosis force scholars to put changes in people's gendered and sexualed self-perceptions at the centre of their analytical and therapeutic interest since it is in and through these self-perceptions that we all are intimate with others, be that partners, lovers, friends, medical professionals or even social institutions and society itself. For gender studies scholars, the performative effects of diagnosis re-instate an analytical openness for the exploration of how gender and sexuality as particular normative dimensions of social life take hold in people's intimate lives and what difference medical diagnoses and their politics and logics make in that process. So, rather than foreclosing the analysis of (bio)medicalization in terms of a critique of the perpetuation of patriarchal and cis- and heteronormative sociality, the performative effects of diagnosis as an analytical tool allows scholars to ask what changes are taking place in people's intimate lives, no matter whether scholars themselves think of these changes as desirable or not or whether or not they deem them subversive (enough). Asking these questions in such an open sense is neither naïve nor uncritical. Rather, it is important to pose and explore these questions openly if one wants to be able to confront the endurance of cis- and heteronormativity in all its varieties. Biopolitical and cis- and heteronormative normalcy take many forms, and employing the performative effects of diagnosis as an analytical tool can help to develop an adequate understanding of their persistence, change, and subversion.

\section{Notes}

1 The term sexualed refers to "generic meanings and activities in relation to sexuality" just as the term gendered does so in relation to gender (Hearn 2014, 402). 


\section{References}

Burke, M. C. 2011. Resisting pathology: GID and the contested terrain of diagnosis in the transgender rights movement. Advances in Medical Sociology. 12, 183-210.

Butler, J. 1986. Sex and Gender in Simone de Beauvoir's Second Sex. Yale French Studies. 72, 35-49. DOI: $10.2307 / 2930225$

Butler, J. 1990. Gender Trouble. Feminism and the Subversion of Identity. New York: Routledge.

Butler, J. 1993. Bodies That Matter. On the discursive limits of sex. New York \& London: Routledge.

Carrigan, T., Connell, B., \& Lee, J. 1985. Toward a New Sociology of Masculinity. Theory and Society. 14 (5), 551-604.

Clarke, A. E. 1998. Disciplining reproduction: modernity, American life sciences, and "the problems of sex". Berkeley: University of California Press.

Clarke, A. E., Mamo, L., Fosket, J. R., Fishman, J., \& Shim, J. K., eds. 2010. Biomedicalization: Technoscience, Health, and IIIness in the U.S. Durham: Duke University Press.

Clarke, A. E., Shim, J. K., Mamo, L. , Fosket, J. R., \& Fishman, J. R. 2003. Biomedicalization: Technoscientific Transformations of Health, Illness, and U.S. Biomedicine. American Sociological Review. 68 (2), 161-194.

Comella, L. 2017. Vibrator Nation: How Feminist Sex-Toy Stores Changed the Business of Pleasure. Durham: Duke University Press.

Conrad, P. 2007. The Medicalization of Society: On the Transformation of Human Conditions into Treatable Disorders. Baltimore: The Johns Hopkins University Press.

Crenshaw, K. 1991. Mapping the Margins: Intersectionality, Identity Politics, and Violence against Women of Color. Stanford Law Review. 43 (6), 1241-1299.

Dean, T. 2015. Mediated intimacies: Raw sex, Truvada, and the biopolitics of chemoprophylaxis. Sexualities. 18 (1-2), 224-246. DOI: 10.1177/1363460715569137

Dodson, B. 2004. We Are All Quite Queer. Journal of Bisexuality. 4 (3-4), 155-163. DOI: 10.1300/ J159v04n03_12

Dworkin, A. 1981. Pornography: Men Possessing Women. London: The Women's Press.

Foucault, M. 1990. The History of Sexuality. Volume 1: An Introduction. New York: Vintage Books.

Franklin, S. 1997. Embodied progress: a cultural account of assisted conception. New York: Routledge.

Franklin, S. \& McNeil, M. 1988. Reproductive Futures: Recent Literature and Current Feminist Debates on Reproductive Technologies. Feminist Studies. 14 (3), 545-560.

Germon, J. 2009. Gender: a genealogy of an idea. New York: Palgrave Macmillan.

Goldie, T. 2014. The Man Who Invented Gender: Engaging the Ideas of John Money. Vancouver: UBC Press.

Holm, S. 2017. Fleshing out the self: Reimagining intersexed and trans embodied lives through (auto)biographical accounts of the past. Department of Thematic Studies - Tema Genus, Linköping University, Linköping.

Horncastle, J. 2018. Busting Out: Happenstance Surgery, Clinic Effects, and the Poetics of Genderqueer Subjectivity. TSQ: Transgender Studies Quarterly. 5 (2), 251-267. DOI: 10.1215/23289252-4348684

Inch, E. 2016. Changing Minds: The Psycho-Pathologization of Trans People. International Journal of Mental Health. 45 (3), 193-204. DOI: 10.1080/00207411.2016.1204822

Inhorn, M. C. 2012. The New Arab Man: Emergent Masculinities, Technologies, and Islam in the Middle East. Princeton: Princeton University Press.

Johnson, A. H. 2019. Rejecting, reframing, and reintroducing: trans people's strategic engagement with the medicalisation of gender dysphoria. Sociology of Health \& IIIness. Early Online View. DOI: 10.1111/14679566.12829

Jutel, A. G. 2011. Putting a name to it: diagnosis in contemporary society. Baltimore: Johns Hopkins University Press. 
Katz, J. 1996. The invention of heterosexuality. New York: Plume.

Kimmel, M. S. 1987. Men's Responses to Feminism at the Turn of the Century. Gender \& Society. 1 (3), 261 283. DOI: $10.1177 / 089124387001003003$

Koch, L. 1990. IVF - An irrational choice? Reproductive and Genetic Engineering: Journal of International Feminist Analysis. 3, 225-232.

MacKinnon, C. A. \& Dworkin, A. 1997. In Harm's Way: The Pornography Civil Rights Hearings. Cambridge: Harvard University Press.

Martin, E. 2001. The Woman in the Body. A Cultural Analysis of Reproduction. Boston: Beacon Press.

Martinez-Lacabe, A. 2019. The non-positive antiretroviral gay body: the biomedicalisation of gay sex in England. Culture, Health \& Sexuality. 21 (10), 1-14. DOI: 10.1080/13691058.2018.1539772

Millett, K. 1970. Sexual Politics. London: Rupert Hart-Davis.

Mohr, S. 2018. Being A Sperm Donor: Masculinity, Sexuality, and Biosociality in Denmark. New York: Berghahn Books.

Ortner, S. B. 1972. Is Female to Male as Nature Is to Culture? Feminist Studies. 1 (2), 5-31.

Oudshoorn, N. 2003. The male pill: a biography of a technology in the making. Durham: Duke University Press.

Paine, E. A. 2018. Embodied disruption: "Sorting out" gender and nonconformity in the doctor's office. Social Science \& Medicine. 211, 352-358. DOI: 10.1016/j.socscimed.2018.06.039

Parsons, T. 2005. The Social System. London: Routledge.

Plemons, E. 2017. The Look of a Woman: Facial Feminization Surgery and the Aims of Trans-Medicine. Durham: Duke University Press.

Plemons, E. 2014. Description of sex difference as prescription for sex change: On the origins of facial feminization surgery. Social Studies of Science. 44 (5), 657-679.

Rabinow, P. 1996. Artificiality and Enlightenment: From Sociobiology to Biosociality. In: Rabinow, P. Essays on the Anthropology of Reason. Princeton: Princeton University Press, 91-111.

Rapp, R. 1999. Testing women, testing the fetus: the social impact of amniocentesis in America. London: Routledge.

Robertson, S. 2007. Understanding Men and Health: Masculinities, Identity and Well-being. Maidenhead: Open University Press.

Rosenfeld, D. \& Faircloth, C. A. eds. 2006. Medicalized Masculinities. Philadelphia: Temple University Press.

Rubin, G. 1975. The Traffic in Women: Notes on the 'Political Economy' of Sex. In: Reiter, R. R. ed. Toward an Anthropology of Women. New York: Monthly Review Press, 157-210.

Rubin, G. 1984. Thinking Sex: Notes for a Radical Theory of the Politics of Sexuality. In: Vance, C. S. ed. Pleasure and Danger: exploring female sexuality, New York: Routledge \& Kegan Paul, 267-319.

Stryker, S. 2008. Transgender History. Berkley: Seal Press.

Taussig, K.-S., Hoeyer, K., \& Helmreich, S. 2013. The Anthropology of Potentiality in Biomedicine: An Introduction to Supplement 7. Current Anthropology. 54 (S7), S3-S14. DOI: 10.1086/671401

Terry, J. 1999. An American obsession: science, medicine, and homosexuality in modern society. Chicago: The University of Chicago Press.

Thompson, C. 2005. Fertile ground: feminists theorize reproductive technologies. In: Thompson, C. Making parents: the ontological choreography of reproductive technologies. Cambridge: MIT Press, 55-75.

Wentzell, E. A. 2013. Maturing Masculinities. Aging, Chronic Illness, and Viagra in Mexico. Durham: Duke University Press.

West, C. \& Zimmerman, D. H. 1987. Doing Gender. Gender and Society. 1 (2), 125-151.

Young, I., Flowers, P. \& McDaid, L. 2016. Can a pill prevent HIV? Negotiating the biomedicalisation of HIV prevention. Sociology of Health \& IIIness. 38 (3), 411-425. DOI: 10.1111/1467-9566.12372

Zola, I. K. 1972. Medicine as an institution of social control. The Sociological Review. 20 (4), 487-504. 